\title{
Development of cement free binders: activation of circulating fluidized bed combustion boilers fly ash
}

\author{
P. PAAVER ${ }^{1}$ AND K. KIRSIMÄE ${ }^{1}$
}

${ }^{1}$ Department of Geology, Tartu University, 50411 Tartu,

Estonia (*correspondence: peeter.paaver@ut.ee)

Increasing pressure on the reducing cement clinker production, the second largest industrial $\mathrm{CO}_{2}$ emitter, drives the research and innovation in finding alternative binders.

There are different ways to reduce classical cement clinker uses including its partial to full replacement by supplementary cementitious materials and/or development of alternative binders with smaller $\mathrm{CO}_{2}$ footprint than of cement clinker production. Fly ash along with granulated blastfurnace slag has been widely used supplements of cement clinker but utilization rate for fly ash is only $30 \%$, mainly because of its largely variable properties resulting from use of different fuels and firing technologies. The worst case are the fly ashes from energy efficient and low $\mathrm{SO}_{2}$ and $\mathrm{NO}_{\mathrm{x}}$ emission fluidized bed (FB) combustion with limited usability in cement and concrete composition, mainly because of their variable composition and low reactivity.

In this contribution we show that $\mathrm{CaO}$ free and sulphate rich FB combustion fly ashes can be succesfully upgraded both in terms of final compressive strength as well as the strength development by only a short mechanical activation without any chemical activation or blending, and further enhanced by moderate alkali activation achieving compressive strenghts comperative to ordinary portland cement.

The strenght development in activated FB fly ash is provided by rapid formation ettringite similar to calcium sulfoaluminate cements, and proceeded with hydration of silicate pahases and formation of $\mathrm{C}-\mathrm{S}-\mathrm{H}$ gel providing further compressive strenght increase up to $60 \mathrm{MPa}$. 